\title{
Left ventricle mass by cardiac magnetic resonance and echocardiography: the multi- ethnic study of atherosclerosis
}

\author{
Anderson C Armstrong ${ }^{1,2^{*}}$, Ola Gjesdal ${ }^{1}$, Andre Almeida ${ }^{1}$, Colin O Wu ${ }^{4}$, Lyndia Brumback ${ }^{3}$, Joao A Lima ${ }^{1}$ \\ From 15th Annual SCMR Scientific Sessions \\ Orlando, FL, USA. 2-5 February 2012
}

\section{Background}

Cardiac magnetic resonance (CMR) is the gold standard imaging method to assess left ventricular mass (LVM), but M-mode echocardiography is more common during clinical practice. Proposed methods to normalize LVM to anthropometric measures provide different cut-off values for LV hypertrophy (LVH). We compare LVM assessed by echocardiography and CMR and evaluate the level of agreement for classification of LVH.

\section{Methods}

A randomized subsample of African-American and Caucasian participants free of clinical cardiovascular disease from the Multi-Ethnic Study of Atherosclerosis (MESA) had echocardiography and CMR performed on the same day at the Johns Hopkins Hospital (JHH), Baltimore, MD. LVM was assessed by echocardiography as recommended by the American Society of Echocardiography. By CMR, short-axis images covering the entire LV were acquired; the difference between epicardial and endocardial areas for all slices was multiplied by the slice thickness $(6 \mathrm{~mm})$ and section gap $(4 \mathrm{~mm})$, and then multiplied by the specific gravity of myocardium (1.04 $\mathrm{g} / \mathrm{ml}$ ), with exclusion of papillary muscle mass. LVH was defined according to normalization by body surface area (BSA), height ${ }^{1.7}$, height ${ }^{2.7}$, or by the expected LVM (95th percentile of subjects free of co-morbidities). LVM assessments were compared using Pearson's correlation, intraclass correlation coefficient (ICC), and Bland-Altman plots. The percent agreement and the Cohen's Kappa coefficient were calculated to evaluate the agreement of LVH classification.

${ }^{1}$ Cardiovascular Imaging, Johns Hopkins Hospital, Baltimore, MD, USA Full list of author information is available at the end of the article

\section{Results}

A total of 155 MESA participants $(66.3 \pm 8.9$ years; $41 \%$ males; $53.1 \%$ Caucasian) were included. A moderately strong correlation was found between LVM assessed by echocardiography and CMR ( $\mathrm{r}=0.66, \mathrm{p}<0.001$, Fig. $1 \mathrm{a})$, the ICC was 0.48 (95\% CI 0.29, 0.68). The Bland-Altman plot demonstrated overestimation of LVM by echocardiography relative to CMR (33.1g, 95\% CI -40.6, 106.7g, Figure 1b). CMR assessment demonstrated $5.8 \% \mathrm{LVH}$ when normalized by BSA; $6.4 \%$ by height ${ }^{1.7} ; 5.8 \%$ by height ${ }^{2.7}$; and $3.2 \%$ by expected LVM. Assessed by echocardiography, $28.4 \%$ had LVH normalized by BSA; $38.7 \%$ by height ${ }^{1.7} ; 23.2 \%$ by height ${ }^{2.7}$; and $17.4 \%$ by expected LVM. The percent of agreed classification ranged from 93 to $97 \%$ using CMR-derived parameters; 79 to $94 \%$ using echocardiographic assessment; and 59 to $81 \%$ between CMR and echocardiographic assessments. The Kappa coefficient for comparing CMR and echocardiography was statistically significant only when indexed by BSA (table 1 ).

\section{Conclusions}

LV mass assessed by echocardiography and CMR demonstrated good correlation. The prevalence of $\mathrm{LVH}$ was lower when assessed by CMR. Higher agreement was present when the techniques were compared separately and lower for comparisons between echocardiography and CMR. Due to importance of myocardial hypertrophy for clinical and research purposes, standardization of the assessment by CMR, by echocardiography, and across modalities is encouraged.

\section{Funding}

National Heart,Lung, and Blood Institute. 

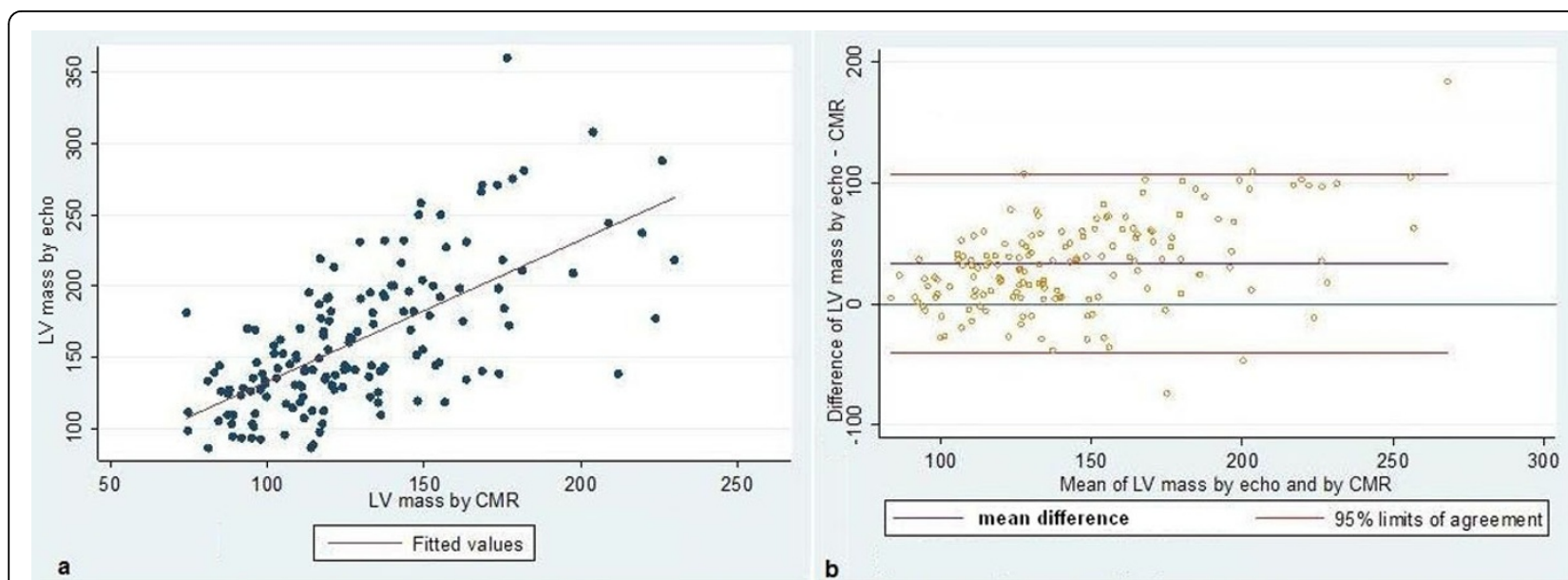

Figure 1 LVM assessed by echocardiography and CMR: scatter plot for linear correlation (a) and Bland-Altman plots for agreement (b).

Table 1 Proportion of agreed classification (below diagonal) and Kappa coefficient of agreement (above diagonal) for the classification of LV hypertrophy according to image methodology and normalization procedure.

\begin{tabular}{|c|c|c|c|c|c|c|c|c|c|}
\hline \multicolumn{2}{|c|}{ Normalization Methodology } & \multicolumn{4}{|c|}{ Cardiac Magnetic Resonance } & \multicolumn{4}{|c|}{ Echocardiography } \\
\hline & BSA & Expected & height^1.7 & height^2.7 & BSA & height^1.7 & height^2.7 & Expected & \\
\hline \multirow[t]{4}{*}{ CMR } & BSA & * & $0.70+$ & $0.38+$ & $0.41+$ & $0.10 \S$ & 0.017 & 0.09 & 0.03 \\
\hline & Expected & $97 \%$ & * & $0.37+$ & $0.55+$ & -0.02 & 0.002 & 0.04 & 0.008 \\
\hline & height^1.7 & $93 \%$ & $94 \%$ & * & $0.61+$ & -0.35 & -0.03 & -0.02 & -0.04 \\
\hline & height^$\wedge 2.7$ & $94 \%$ & $96 \%$ & $96 \%$ & $*$ & -0.02 & 0.02 & 0.04 & 0.02 \\
\hline \multirow[t]{4}{*}{ Echo } & BSA & $72 \%$ & $70 \%$ & $68 \%$ & $68 \%$ & $*$ & $0.57 \dagger$ & $0.76+$ & $0.70 \dagger$ \\
\hline & height^1.7 & $61 \%$ & $61 \%$ & $59 \%$ & $61 \%$ & $81 \%$ & * & $0.62+$ & $0.50 \dagger$ \\
\hline & height^2.7 & $76 \%$ & $76 \%$ & $73 \%$ & $75 \%$ & $91 \%$ & $83 \%$ & * & $0.82 \dagger$ \\
\hline & Expected & $79 \%$ & $81 \%$ & $77 \%$ & $79 \%$ & $89 \%$ & $79 \%$ & $94 \%$ & * \\
\hline
\end{tabular}

CMR - Cardiac Magnetic Resonance; Echo - Echocardiography $t p<0.0001 ; \S p<0.05$

Author details

${ }^{1}$ Cardiovascular Imaging, Johns Hopkins Hospital, Baltimore, MD, USA.

${ }^{2}$ Cardiology, Universidade Federal do Vale do São Francisco, Petrolina, Brazil.

${ }^{3}$ Biostatistics, University of Washington, Seattle, WA, USA. ${ }^{4} \mathrm{OD} / \mathrm{NHLBI} / \mathrm{NIH}$,

Bethesda, MD, USA.

Published: 1 February 2012

doi:10.1186/1532-429X-14-S1-P296

Cite this article as: Armstrong et al:: Left ventricle mass by cardiac magnetic resonance and echocardiography: the multi-ethnic study of atherosclerosis. Journal of Cardiovascular Magnetic Resonance 201214 (Suppl 1):P296.
Submit your next manuscript to BioMed Central and take full advantage of:

- Convenient online submission

- Thorough peer review

- No space constraints or color figure charges

- Immediate publication on acceptance

- Inclusion in PubMed, CAS, Scopus and Google Scholar

- Research which is freely available for redistribution 